\title{
Neurology
}

\section{Effect of chlorzoxazone in patients with downbeat nystagmus: A pilot trial}

Katharina Feil, Jens Claaßen, Stanislavs Bardins, et al.

Neurology 2013;81;1152-1158 Published Online before print August 23, 2013

DOI 10.1212/WNL.0b013e3182a55f6d

This information is current as of August 23, 2013

The online version of this article, along with updated information and services, is located on the World Wide Web at:

http://www.neurology.org/content/81/13/1152.full.html

Neurology ${ }^{\circledR}$ is the official journal of the American Academy of Neurology. Published continuously since 1951, it is now a weekly with 48 issues per year. Copyright (C) 2013 American Academy of Neurology. All rights reserved. Print ISSN: 0028-3878. Online ISSN: 1526-632X.

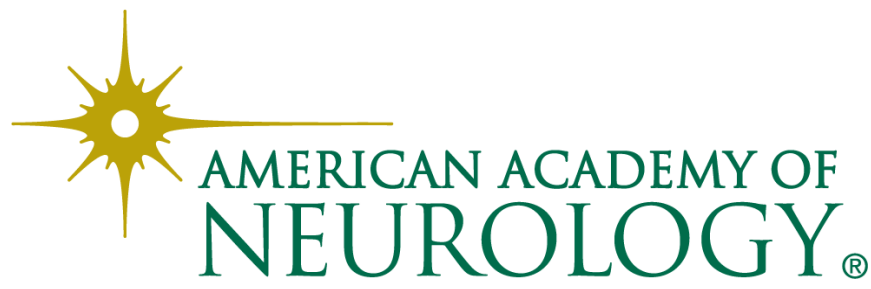


Katharina Feil, MD* Jens Claaßen, MD* Stanislavs Bardins Julian Teufel, MD Siegbert Krafczyk Erich Schneider, PhD Roman Schniepp, MD, MD

Klaus Jahn, MD

Roger Kalla, MD

Michael Strupp, MD

Correspondence to

Dr. Feil:

katharina.feil@med.uni-

muenchen.de

\title{
Effect of chlorzoxazone in patients with downbeat nystagmus
}

\author{
A pilot trial
}

$\underline{\underline{\underline{\underline{1}}}}$

ABSTRACT

Objective: Downbeat nystagmus (DBN) is the most frequent form of acquired persisting fixation nystagmus with different symptoms such as unsteadiness of gait, postural instability, and blurred vision with reduced visual acuity (VA) and oscillopsia. However, different symptomatic therapeutic principles are required, such as 3,4-diaminopyridine and 4-aminopyridine, that effectively suppress DBN. Chlorzoxazone $(\mathrm{CHZ})$ is a nonselective activator of small conductance calcium-activated potassium (SK) channels that modifies the activity of cerebellar Purkinje cells. We evaluated the effects of this agent on DBN in an observational proof-of-concept pilot study.

Methods: Ten patients received CHZ 500 mg 3 times a day for 1 or 2 weeks. Slow-phase velocity of DBN, VA, postural sway, and the drug's side effects were evaluated. Recordings were conducted at baseline, 90 minutes after first administration, and after 1 or 2 weeks.

Results: Mean slow-phase velocity significantly decreased from a baseline of $2.74 \% \pm 2.00$ to $2.29 \% \pm 2.12$ (mean \pm SD) 90 minutes after first administration and to $2.04 \% \pm 2.24(p<$ 0.001 ; post hoc both $p=0.024$ ) after long-term treatment. VA significantly increased and postural sway in posturography showed a tendency to decrease on medication. Fifty percent of patients did not report any side effects. The most common reported side effect was abdominal discomfort and dizziness.

Conclusions: The treatment with the SK-channel activator $\mathrm{CHZ}$ is a potentially new therapeutic agent for the symptomatic treatment of DBN.

Classification of evidence: This study provides Class IV evidence that $\mathrm{CHZ} 500 \mathrm{mg} 3$ times a day may improve eye movements and visual fixation in patients with DBN. Neurology ${ }^{\circledR}$ 2013;81:1152-1158

\section{GLOSSARY}

4-AP = 4-aminopyridine; $\mathbf{C H Z}=$ chlorzoxazone; 3,4-DAP = 3,4-diaminopyridine; $\mathbf{D B N}=$ downbeat nystagmus; EA2 = episodic ataxia type 2; PC = Purkinje cell; $\mathbf{S K}=$ small conductance calcium-activated potassium; $\mathbf{S P V}=$ slow-phase velocity; $\mathrm{VA}=$ visual acuity

Downbeat nystagmus (DBN) is the most frequent form of acquired persisting fixation nystagmus. ${ }^{1-3}$ The most common symptoms are unsteadiness of gait, postural instability, blurred vision with reduced visual acuity (VA), and vertical oscillopsia. ${ }^{1,2} \mathrm{DBN}$ is most often caused by impaired function of the cerebellar flocculus/paraflocculus. ${ }^{4}$ The etiology is diverse. In approximately $40 \%$ of patients, no underlying pathology can be found. ${ }^{3}$ Of the different medications that have been used to treat DBN, ${ }^{5}$ GABAergic, glutamatergic, and cholinergic drugs showed only moderate success. ${ }^{5}$ However, 3,4-diaminopyridine (3,4-DAP) and 4-aminopyridine (4-AP) effectively suppress DBN. ${ }^{5}$

The small conductance calcium-activated potassium (SK) channel activator chlorzoxazone (CHZ) reduced burst-like firing and thereby decreased irregular Purkinje cell (PC) firing in P/Q calcium-channel $C A C N A 1 a^{5218 \mathrm{~L}}$ mutants. $^{5-8} \mathrm{~A}$ mechanism similar to that of Kv1.5 potassiumchannel blockers ${ }^{5-7}$ is assumed for the effects of aminopyridines in episodic ataxia type 2 (EA2). $\mathrm{CHZ}$ has already been used as a centrally acting agent for painful musculoskeletal conditions and muscle spasm, ${ }^{9,10}$ and is an over-the-counter drug approved by the US Food and Drug Administration $^{10}$ (for reference, see http://www.drugs.com/pro/chlorzoxazone.html). Based on the

*These authors contributed equally to this work.

From the Department of Neurology and German Center for Vertigo and Balance Disorders, University Hospital Munich, Campus Grosshadern, Munich, Germany.

Go to Neurology.org for full disclosures. Funding information and disclosures deemed relevant by the authors, if any, are provided at the end of the article. 


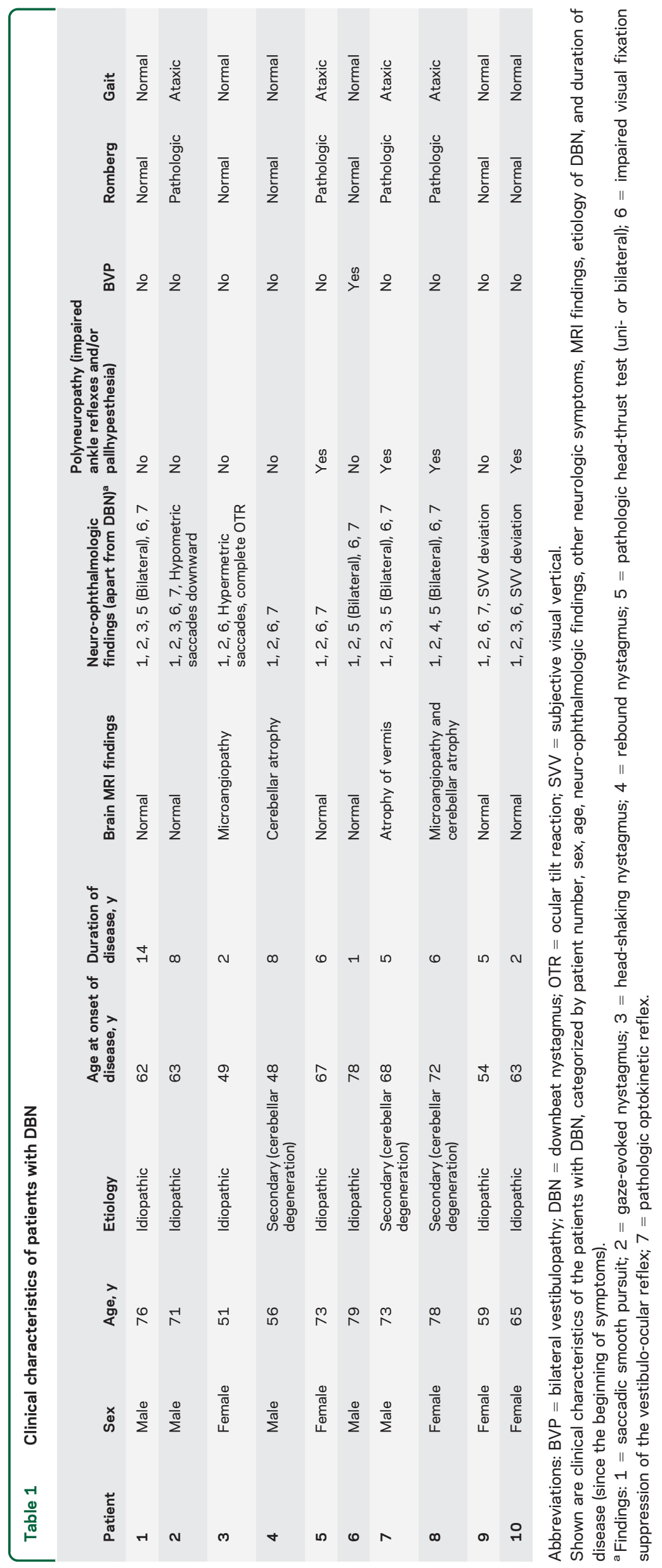

above-mentioned theoretical and pharmacologic effect and in particular its action on PCs, the effectiveness in patients with DBN was tested.

METHODS Level of evidence. The aim of this Class IV evidence study was to evaluate the effect of CHZ $500 \mathrm{mg} 3$ times a day orally in terms of eye movements, postural sway, and visual fixation in patients with DBN.

Standard protocol approvals, registration, and patient consents. This pilot trial was only an observational study. All patients gave their informed consent for the compassionate use of $\mathrm{CHZ}$.

Concept of the pilot trial. Ten patients (aged 48-78 years, 5 females; for further details, see table 1) received $500 \mathrm{mg}$ of $\mathrm{CHZ} 3$ times a day for 1 or 2 weeks. Measurements were conducted at baseline, after first drug administration, and after 1 to 2 weeks of treatment. Measurements were performed 90 minutes after first administration as peak levels of $\mathrm{CHZ}$ may be reached approximately 1 to 2 hours after oral administration. ${ }^{11}$ After this first dose of the medication, the patients took another tablet in the evening; from day 2 of the observational period, the patients had the full dosage of $\mathrm{CHZ} 500 \mathrm{mg} 3$ times a day. Eye movements were recorded with 3-dimensional video-oculography (EyeSeeCam) (see reference 12). VA was measured using the Snellen chart positioned at a distance of $6 \mathrm{~m}$ and was specified as a decimal. Thus, optimal VA is 1.0. Posturographic measurements were conducted in the upright position with eyes open and head extended backward $\left(30^{\circ}\right)$. The 2 conditions included standing either on firm ground (condition 1) or on a slab of foam rubber (condition 2) (see reference 13). The body sway of 30 seconds of the posturographic measurement provided the sway path values $(\mathrm{m} / \mathrm{min})$. For safety reasons, blood testing of liver enzymes, sodium, potassium, creatinine, and urea was performed. The patients used the 28-item Vestibular Disorders Activities of Daily Living Scale ${ }^{14}$ to determine their functional burden of disease on a 10-point scale at baseline and during treatment.

Statistical analysis. Figures were designed using Prism version 5 (GraphPad Software, Inc., La Jolla, CA). Statistical analysis was done using SPSS version 20 (IBM Corp., Armonk, NY). Data were not normally distributed; hence, nonparametric statistical tests were performed. To look for differences between baseline and the 2 measurements under medication, the Friedman test with $\chi^{2}$ test statistics was applied. For individual post hoc comparisons, the nonparametric Wilcoxon test statistics with Bonferroni correction were applied. In the eye-movement data, slow-phase velocity (SPV) of vertical eye movements was the dependent variable. DBN indicated by mean SPV (degrees/s) appears as a positive value, whereas the absence of DBN is a near zero value. For VA and postural sway, the same statistical analysis as in SPV was applied. The significance level was set to 5\%. Patients who did not complete the long-term treatment were not included in the baseline data for the long-term treatment analysis.

RESULTS Effects of CHZ on SPV of DBN. Mean SPV decreased from baseline of $2.74 \% \mathrm{~s} \pm 2.00$ (mean \pm SD) to $2.29 \% \pm 2.12$ after the first administration of $\mathrm{CHZ} 500 \mathrm{mg}$ and from $3.09^{\circ} \mathrm{s} \pm 2.19$ to $2.04^{\circ} \mathrm{s} \pm$ 2.24 after long-term treatment. There was a significant overall decrease (Friedman test with $\chi^{2}$ statistics $=$ 8.86, $p<0.001, \mathrm{n}=7$ ) with a significant post hoc difference between baseline and 90 minutes after first administration $(p=0.024)$ as well as after long-term 
treatment $(p<0.001)$. The patients showed a mean $\Delta$ SPV of $28 \%$ after first administration and $44 \%$ after long-term treatment. Mean SPV decreased by $\geq 40 \%$ in $40 \%$ of patients after first administration and in 4 of 7 subjects after long-term treatment. The remainder of the patients showed a $10 \%$ to $30 \%$ decrease of mean SPV after long-term treatment (see figure 1 and figure 2, A and B). In total, $50 \%$ of patients had a decrease of mean SPV of $\geq 30 \%$ and $30 \%$ of patients of $\geq 50 \%$ after the first administration of $\mathrm{CHZ}$.

Effects of CHZ on VA. VA increased from $0.73 \pm 0.24$ at baseline to $0.84 \pm 0.20$ after first administration and from $0.72 \pm 0.24$ to $0.75 \pm 0.25$ after long-term treatment. There was a significant overall increase (Friedman test with $\chi^{2}$ statistics $=7.00, p=0.047$, $\mathrm{n}=7$ ) with a significant post hoc difference between baseline and VA 90 minutes after administration of $\mathrm{CHZ}(p=0.01)$ as well as between baseline and after long-term treatment $(p=0.02)$ (see figure 2C).

Effects of $\mathrm{CHZ}$ on postural sway. In condition 1, sway path decreased from $1.68 \pm 0.95 \mathrm{~m} / \mathrm{min}$ to $1.26 \pm$ $0.65 \mathrm{~m} / \mathrm{min} 90$ minutes after first administration and from $1.36 \pm 0.63 \mathrm{~m} / \mathrm{min}$ to $1.00 \pm 0.33 \mathrm{~m} / \mathrm{min}$ after long-term treatment. There was a marginal significant overall decrease (Friedman test with $\chi^{2}$ statistics $=6.00, p=0.05, \mathrm{n}=4$ ) with a marginal significant post hoc difference between baseline and first administration $(p=0.08)$ but no significance between baseline and after long-term treatment ( $p=$ 0.12 ) (see figure $2 \mathrm{D}$ ). In condition 2 , sway path decreased from $3.80 \pm 2.11 \mathrm{~m} / \mathrm{min}$ to $3.17 \pm$ $2.07 \mathrm{~m} / \mathrm{min}$ and from $4.31 \pm 2.29 \mathrm{~m} / \mathrm{min}$ to $2.81 \pm 1.31 \mathrm{~m} / \mathrm{min}$. There was a significant overall decrease (Friedman test with $\chi^{2}$ statistics $=6.50$, $p=0.039, \mathrm{n}=4$ ) with a marginal significant post hoc difference of sway between baseline and first administration $(p=0.08)$ but no significance between baseline and long-term treatment $(p=0.435)$.

Side effects. All patients had normal blood test results. Fifty percent of patients reported abdominal discomfort during the treatment period (patients 5, 7, 8, 9, and 10). Patient 2 stopped treatment because of noncompliance, patient 6 because of hospitalization for formerly known atrial fibrillation, and patient 8 because of abdominal discomfort (see table 2). Regarding the Vestibular Disorders Activities of Daily Living Scale, there was no significant difference between the scores of the patients at baseline and under treatment

Figure 1 Original recordings of vertical eye positions of different patients taking chlorzoxazone $500 \mathrm{mg} 3$ times a day

Patient no. 7
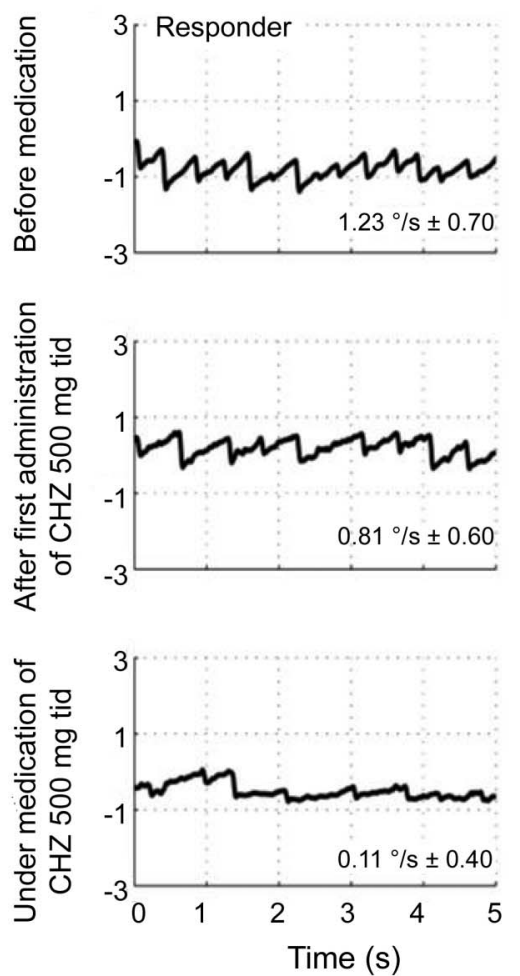

Patient no. 10
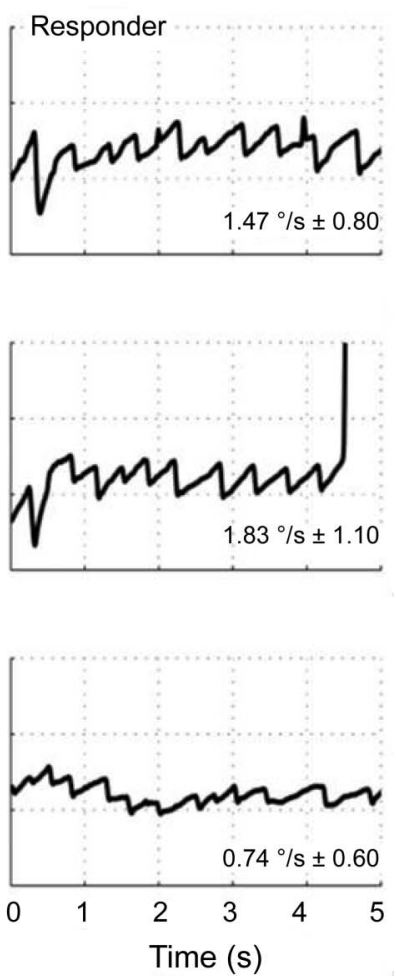

Patient no. 4
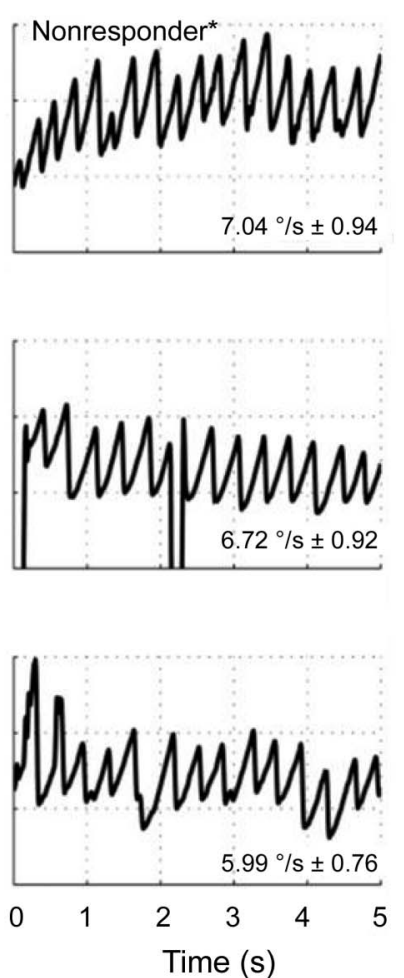

Original recording of the vertical eye position with mean slow-phase velocity of downbeat nystagmus of 3 different patients $(4,7$, and 10) at the different time points: before medication, 90 minutes after first administration of chlorzoxazone (CHZ) $500 \mathrm{mg} 3$ times a day (tid), and on medication with $\mathrm{CHZ} 500 \mathrm{mg}$ tid for 1 or 2 weeks. ${ }^{*}$ Nonresponder, treatment period of 1 week. Patients 7 and 10 (responder) received $\mathrm{CHZ}$ for 2 weeks. 


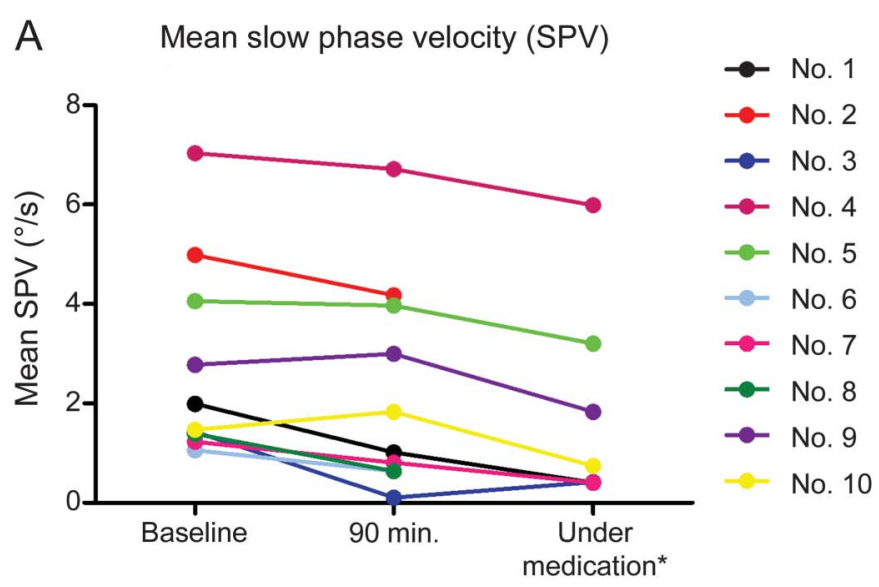

C

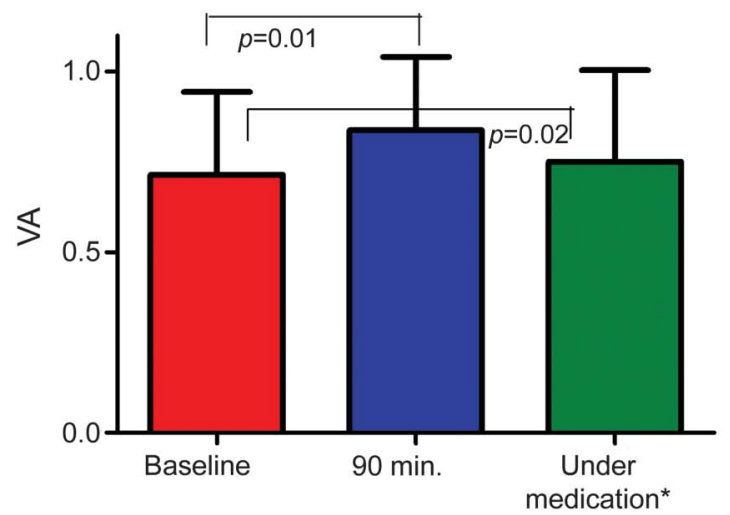

B Mean slow phase velocity (SPV)

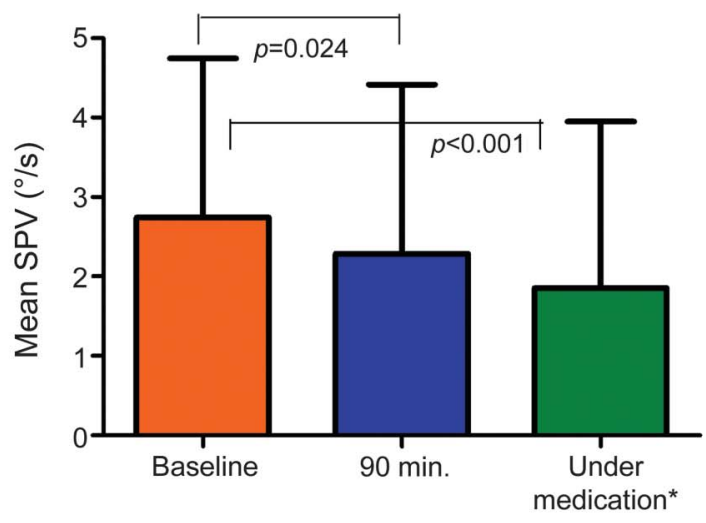

D Posturography

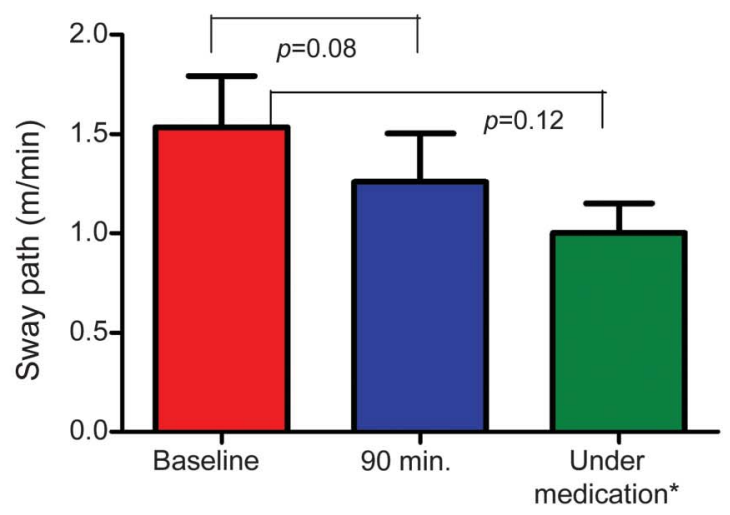

Effect of chlorzoxazone (CHZ) on mean slow-phase velocity (SPV) (A, B), visual acuity (VA) (C), and posturography (D). Measurements performed at baseline, 90 minutes after medication, and on medication (1 or 2 weeks of $\mathrm{CHZ} 500 \mathrm{mg} 3$ times a day). Posturography only shown in condition 1: upright position with eyes open and head inclined backward $\left(30^{\circ}\right)$ on firm ground. *On medication: 1 or 2 weeks under $\mathrm{CHZ} 500$ mg 3 times a day. VA improved on medication.

$(p=0.691)$, but a positive tendency was shown in some patients $(3,4,5,9$, and 10).

DISCUSSION This observational proof-of-principle pilot study showed that $\mathrm{CHZ}$ caused a significant decrease of intensity of DBN and an improvement of VA. Postural imbalance also improved. Forty percent of patients had a decrease of $\geq 40 \%$ of mean SPV during treatment with $\mathrm{CHZ}$. In $60 \%$ of patients, mean SPV decreased by $>50 \%$ and in $70 \%$ by $>40 \%$ during treatment with 3,4-DAP. ${ }^{15}$ In comparison, $40 \%$ of the patients receiving $4-\mathrm{AP}$ showed a decrease of mean SPV of $>50 \% .{ }^{1}$ Thus, $\mathrm{CHZ}$ at the doses used might be less effective than aminopyridines. $^{1,2,15}$ Animal experiments suggest that $\mathrm{CHZ}$ could be more effective than 4-AP. ${ }^{6,7}$

What is the assumed mechanism of $\mathrm{CHZ}$ in $\mathrm{DBN}$ ? In the tottering mouse, an animal model of $\mathrm{EA} 2$, it was shown that $\mathrm{CHZ}$ (as well as 4-AP) can prevent attacks (without an additive effect) ${ }^{6,7}$; oral administration of $\mathrm{CHZ}$ also improved baseline motor performance and reduced the severity and duration of episodes of dyskinesia without producing any adverse effects. Single-cell recordings revealed that in this animal model the firing rate of PCs is very irregular. The loss of the precision of pace-making in EA2 is the consequence of reduced activation of calcium-dependent potassium channels by the smaller calcium current. As shown in animal experiments, despite contrasting pharmacologic effects of 4-AP (potassium-channel blocker) and CHZ (unspecific SK-channel activation), both can restore the precision of pacemaking of PCs. ${ }^{7}$ For $\mathrm{CHZ}$, the assumed pharmacologic mechanism is an increase in the magnitude of the potassium currents via SK channels. ${ }^{7}$ This may also be relevant in DBN, which is assumed to be caused by an impaired function of PCs in the flocculus. ${ }^{4}$ In this observational study, patients received $\mathrm{CHZ}, 500 \mathrm{mg} 3$ times a day. The US Food and Drug Administration recommends an adult daily allowance of 250-750 mg orally 3-4 times a day. ${ }^{10}$ With our dosage, $50 \%$ of patients already reported abdominal discomfort, which was probably due to the high initial dose. Perhaps patients would tolerate the drug 
Table 2 Changes of clinical measurements on medication with $\mathrm{CHZ} 500 \mathrm{mg} 3$ times a day

\begin{tabular}{|c|c|c|c|c|c|}
\hline Measurement ${ }^{a}$ & SPV $(\% / s)^{b}$ & $\begin{array}{l}\text { Sway path (m/min) } \\
\text { (cond. } 1 / \text { cond. } 2)^{c}\end{array}$ & Visual acuity & VDADL score & Side effects \\
\hline \multicolumn{6}{|l|}{ Patient 1} \\
\hline 1 & $1.99 \pm 3.92$ & $2.46 / 5.58$ & 0.70 & 2.9 & None \\
\hline 2 & $1.01 \pm 2.41$ & $2.15 / 3.93$ & 0.70 & & \\
\hline 3 & $0.40 \pm 1.19$ & $1.44 / 3.56$ & 0.70 & 3.9 & \\
\hline \multicolumn{6}{|l|}{4} \\
\hline \multicolumn{6}{|l|}{ Patient 2} \\
\hline 1 & $4.99 \pm 1.48$ & $3.43 / 3.40$ & 0.55 & 3.2 & None \\
\hline 2 & $4.18 \pm 0.95$ & $1.92 / 2.64$ & 0.55 & & \\
\hline 3 & & & & & $\begin{array}{l}\text { Stopped medication because of } \\
\text { noncompliance }\end{array}$ \\
\hline 4 & $5.13 \pm 1.44$ & & 0.55 & & \\
\hline \multicolumn{6}{|l|}{ Patient 3} \\
\hline 1 & $1.09 \pm 0.72$ & $1.18 / 2.67$ & 1.00 & 2.4 & None \\
\hline 2 & $0.10 \pm 0.35$ & $1.16 / 2.39$ & 1.00 & & \\
\hline 3 & $0.26 \pm 0.36$ & $1.03 / 2.00$ & 1.00 & 1.6 & \\
\hline \multicolumn{6}{|l|}{4} \\
\hline \multicolumn{6}{|l|}{ Patient 4} \\
\hline 1 & $7.04 \pm 5.94$ & $0.89 / 2.56$ & 0.50 & 4.1 & None \\
\hline 2 & $6.72 \pm 0.92$ & $0.45 / 0.95$ & 0.90 & & \\
\hline 3 & $5.99 \pm 0.76$ & $0.74 / 1.76$ & 0.80 & 3.9 & \\
\hline \multicolumn{6}{|l|}{4} \\
\hline \multicolumn{6}{|l|}{ Patient 5} \\
\hline 1 & $4.06 \pm 0.57$ & $1.06 / 7.76$ & 0.58 & 4.0 & $\begin{array}{l}\text { Abdominal discomfort after } \\
\text { increase of dose (after } 1 \mathrm{wk} \text { ) }\end{array}$ \\
\hline 2 & $3.97 \pm 0.70$ & $0.58 / 7.43$ & 0.60 & & \\
\hline 3 & $3.33 \pm 0.17$ & $0.62 / 4.76$ & 0.60 & 3.4 & \\
\hline 4 & $4.15 \pm 0.65$ & $1.74 / 4.85$ & 0.58 & & \\
\hline \multicolumn{6}{|l|}{ Patient 6} \\
\hline 1 & $1.06 \pm 0.37$ & $1.00 / 2.26$ & 0.68 & 4.0 & None \\
\hline 2 & $0.64 \pm 1.02$ & & 0.70 & & $\begin{array}{l}\text { Stopped medication because of } \\
\text { hospitalization for formerly } \\
\text { known atrial fibrillation }\end{array}$ \\
\hline 3 & $1.66 \pm 0.68$ & $1.30 / 2.95$ & & & \\
\hline 4 & & & 0.70 & & \\
\hline \multicolumn{6}{|l|}{ Patient 7} \\
\hline 1 & $1.23 \pm 0.70$ & $1.76 / 2.85$ & 0.68 & 3.8 & Abdominal discomfort \\
\hline 2 & $0.81 \pm 0.60$ & $1.55 / 2.55$ & 0.89 & & \\
\hline 3 & $0.11 \pm 0.40$ & & 0.70 & & \\
\hline \multicolumn{6}{|l|}{4} \\
\hline \multicolumn{6}{|l|}{ Patient 8} \\
\hline 1 & $1.39 \pm 1.10$ & $1.42 / 2.54$ & 1.00 & 5.9 & $\begin{array}{l}\text { Stopped the treatment because } \\
\text { of abdominal discomfort }\end{array}$ \\
\hline 2 & $0.06 \pm 1.00$ & & 1.00 & & \\
\hline \multicolumn{6}{|l|}{3} \\
\hline 4 & & & & & \\
\hline
\end{tabular}

Continued 
Table 2 Continued

\begin{tabular}{|c|c|c|c|c|c|}
\hline Measurement $^{\mathrm{a}}$ & $\operatorname{SPV}(\% / s)^{b}$ & $\begin{array}{l}\text { Sway path }(\mathrm{m} / \mathrm{min} \text { ) } \\
\text { (cond. } 1 / \text { cond. 2) }\end{array}$ & Visual acuity & VDADL score & Side effects \\
\hline \multicolumn{6}{|l|}{ Patient 9} \\
\hline 1 & $2.78 \pm 0.90$ & $0.66 / 2.64$ & 1.00 & 5.6 & Abdominal discomfort \\
\hline 2 & $3.00 \pm 0.70$ & & 1.00 & & \\
\hline 3 & $1.83 \pm 0.60$ & $1.18 / 1.96$ & 1.00 & 2.5 & \\
\hline \multicolumn{6}{|l|}{4} \\
\hline \multicolumn{6}{|l|}{ Patient 10} \\
\hline 1 & $1.47 \pm 0.80$ & $0.95 / 1.78$ & 0.78 & 2.4 & Abdominal discomfort \\
\hline 2 & $1.83 \pm 1.10$ & $1.01 / 2.31$ & 1.00 & & \\
\hline 3 & $0.74 \pm 0.60$ & & 1.00 & 2.3 & \\
\hline 4 & & & & & \\
\hline
\end{tabular}

Abbreviations: $\mathrm{CHZ}=$ chlorzoxazone; cond. $=$ condition; $\mathrm{SPV}=$ slow-phase velocity; VDADL = Vestibular Disorders Activities of Daily Living.

a Time periods: 1 = baseline; 2 = 90 min after first administration; 3 = after 1 or 2 wk under CHZ 500 mg 3 times a day; 4 = after washout period without medication for at least $4 \mathrm{wk}$.

${ }^{b}$ Mean \pm SD SPV of downbeat nystagmus of patients treated with $\mathrm{CHZ}$ at different time points.

${ }^{\mathrm{c}}$ Cond. 1 = upright position with eyes opened and inclined head on firm ground; cond. 2 = upright position with eyes opened and inclined head on foam ground.

better with a slower titration. Furthermore, $\mathrm{CHZ}$ is not only selective for SK channels but also activates largeconductance potassium ion channels (BK channels). ${ }^{16}$ As selective drugs for SK channels become available, they may be of superior therapeutic efficacy. As a selective positive modulator of calcium-activated potassium channels with positive effects in mouse models of spinocerebellar ataxia type 2 has become available, this would therefore also be a potential candidate for the treatment of DBN. ${ }^{17}$

This proof-of-concept pilot study has some limitations. First, it was not a randomized placebo-controlled clinical trial. Second, only one dosage was tested. Third, the number of patients was low. Fourth, there were not sufficient data for the washout period.

This study shows a significant effect of the nonselective SK-channel activator CHZ in DBN. This is thereby a new therapeutic principle that could be of relevance not only for the treatment of DBN but also for the treatment of other cerebellar disorders, e.g., $\mathrm{EA} 2{ }^{18}$ or cerebellar gait disorders, ${ }^{19}$ which also respond to aminopyridines. Thus, $\mathrm{CHZ}$ could be an alternative symptomatic treatment option for patients with $\mathrm{DBN}$, in whom the use of aminopyridines is limited. It is necessary to further evaluate the effects of $\mathrm{CHZ}$ on DBN in a placebo-controlled, dose-finding trial with additional outcome measures, in particular quality of life.

\section{AUTHOR CONTRIBUTIONS}

K.F. and J.C.: drafting/revising the manuscript for content, including medical writing, study concept, analysis and interpretation of data, acquisition of data. S.B.: revising the manuscript for content, analysis and interpretation of data, acquisition of data. J.T.: drafting/revising the manuscript for content, including medical writing for content. S.K.: revising manuscript for content.
E.S.: drafting/revising the manuscript for content, acquisition of data. R.S., K.J., and R.K.: drafting/revising the manuscript for content, including medical writing for content. M.S.: drafting/revising the manuscript for content, including medical writing for content, critical revision of the manuscript for important intellectual content, study concept/design.

\section{ACKNOWLEDGMENT}

The authors thank Katie Ogston for copyediting the manuscript.

\section{STUDY FUNDING}

Supported by the German Ministry of Education and Research (BMBF), grant 01EO0901, to the German Center for Vertigo and Balance Disorders $\left(\mathrm{IFB}^{\mathrm{LMU}}\right)$.

\section{DISCLOSURE}

K. Feil, J. Claaßen, S. Bardins, J. Teufel, S. Krafczyk, and E. Schneider report no disclosures. R. Schniepp received a grant (money for the institution) from BMBF 01EO0901 (Federal Ministry for Education and Science of Germany). K. Jahn received a grant (money for the institution) from BMBF (Federal Ministry for Education and Science of Germany). R. Kalla received a grant (money for the institution) from BMBF (Federal Ministry for Education and Science of Germany). M. Strupp is Joint Chief Editor of the Journal of Neurology, Editor-in-Chief of Frontiers of Neuro-otology, and Section Editor of F1000. He has received speaker's honoraria from Abbott, UCB, GSK, TEVA, Biogen Idec, Pierre-Fabre, and Hennig Pharma. Go to Neurology.org for full disclosures.

Received March 13, 2013. Accepted in final form June 27, 2013.

\section{REFERENCES}

1. Kalla R, Glasauer S, Buttner U, Brandt T, Strupp M. 4-Aminopyridine restores vertical and horizontal neural integrator function in downbeat nystagmus. Brain 2007; 130:2441-2451.

2. Kalla R, Glasauer S, Schautzer F, et al. 4-Aminopyridine improves downbeat nystagmus, smooth pursuit, and VOR gain. Neurology 2004;62:1228-1229.

3. Wagner JN, Glaser M, Brandt T, Strupp M. Downbeat nystagmus: aetiology and comorbidity in 117 patients. J Neurol Neurosurg Psychiatry 2008;79:672-677. 
4. Kalla R, Deutschlander A, Hufner K, et al. Detection of floccular hypometabolism in downbeat nystagmus by fMRI. Neurology 2006;66:281-283.

5. Strupp M, Thurtell MJ, Shaikh AG, Brandt T, Zee DS, Leigh RJ. Pharmacotherapy of vestibular and ocular motor disorders, including nystagmus. J Neurol 2011;258:12071222.

6. Alvina K, Khodakhah K. The therapeutic mode of action of 4-aminopyridine in cerebellar ataxia. J Neurosci 2010; 30:7258-7268.

7. Alvina K, Khodakhah K. KCa channels as therapeutic targets in episodic ataxia type-2. J Neurosci 2010;30: 7249-7257.

8. Gao Z, Todorov B, Barrett CF, et al. Cerebellar ataxia by enhanced $\mathrm{Ca}(\mathrm{V}) 2.1$ currents is alleviated by $\mathrm{Ca} 2+$-dependent $\mathrm{K}+$-channel activators in Cacnala(S218L) mutant mice. J Neurosci 2012;32:15533-15546.

9. Cao Y, Dreixler JC, Roizen JD, Roberts MT, Houamed KM. Modulation of recombinant small-conductance $\mathrm{Ca}(2+)$ activated $\mathrm{K}(+)$ channels by the muscle relaxant chlorzoxazone and structurally related compounds. J Pharmacol Exp Ther 2001;296:683-689.

10. Chou R, Peterson K, Helfand M. Comparative efficacy and safety of skeletal muscle relaxants for spasticity and musculoskeletal conditions: a systematic review. J Pain Symptom Manage 2004;28:140-175.

11. Bachmann K, Sarver JG. Chlorzoxazone as a single sample probe of hepatic CYP2E1 activity in humans. Pharmacology 1996;52:169-177.
12. Glasauer S, Hoshi M, Kempermann U, Eggert T, Buttner U. Three-dimensional eye position and slow phase velocity in humans with downbeat nystagmus. J Neurophysiol 2003;89: 338-354.

13. Krafczyk S, Tietze S, Swoboda W, Valkovic P, Brandt T. Artificial neural network: a new diagnostic posturographic tool for disorders of stance. Clin Neurophysiol 2006;117: 1692-1698.

14. Cohen HS, Kimball KT. Development of the Vestibular Disorders Activities of Daily Living Scale. Arch Otolaryngol Head Neck Surg 2000;126:881-887.

15. Strupp M, Schuler O, Krafczyk S, et al. Treatment of downbeat nystagmus with 3,4-diaminopyridine: a placebocontrolled study. Neurology 2003;61:165-170.

16. Syme CA, Gerlach AC, Singh AK, Devor DC. Pharmacological activation of cloned intermediate- and small-conductance $\mathrm{Ca}(2+)$-activated $\mathrm{K}(+)$ channels. Am J Physiol Cell Physiol 2000;278:C570-C581.

17. Kasumu AW, Hougaard C, Rode F, et al. Selective positive modulator of calcium-activated potassium channels exerts beneficial effects in a mouse model of spinocerebellar ataxia type 2. Chem Biol 2012;19: $1340-1353$.

18. Strupp M, Kalla R, Claassen J, et al. A randomized trial of 4-aminopyridine in EA2 and related familial episodic ataxias. Neurology 2011;77:269-275.

19. Schniepp R, Wuehr M, Neuhaeusser $M$, et al. 4-Aminopyridine and cerebellar gait: a retrospective case series. J Neurol 2012;259:2491-2493.

\section{Visit the Neurology ${ }^{\circledR}$ Web Site at www.neurology.org}

- Enhanced navigation format

- Increased search capability

- Highlighted articles

- Detailed podcast descriptions

- RSS Feeds of current issue and podcasts

- Personal folders for articles and searches

- Mobile device download link

- AAN Web page links

- Links to Neurology Now ${ }^{\circledR}$, Neurology Today ${ }^{\circledR}$, and Continuum ${ }^{\circledR}$

- Resident \& Fellow subsite

(n) Find Neurology ${ }^{\circledR}$ on Facebook: http://tinyurl.com/neurologyfan

twitter Follow Neurology ${ }^{\circledR}$ on Twitter: https://twitter.com/GreenJournal 


\section{Effect of chlorzoxazone in patients with downbeat nystagmus: A pilot trial}

Katharina Feil, Jens Claaßen, Stanislavs Bardins, et al.

Neurology 2013;81;1152-1158 Published Online before print August 23, 2013

DOI 10.1212/WNL.0b013e3182a55f6d

This information is current as of August 23, 2013

\section{Updated Information \&} Services

\section{References}

\section{Subspecialty Collections}

Permissions \& Licensing

Reprints including high resolution figures, can be found at:

http://www.neurology.org/content/81/13/1152.full.html

This article cites 19 articles, 12 of which you can access for free at:

http://www.neurology.org/content/81/13/1152.full.html\#\#ref-list1

This article, along with others on similar topics, appears in the following collection(s):

\section{All Medical/Systemic disease}

http://www.neurology.org//cgi/collection/all_medical_systemic_d isease

Class IV

http://www.neurology.org//cgi/collection/class_iv

Clinical trials Observational study (Cohort, Case control)

http://www.neurology.org//cgi/collection/clinical_trials_observati onal_study_cohort_case_control

Gait disorders/ataxia

http://www.neurology.org//cgi/collection/gait_disorders_ataxia

Nystagmus

http://www.neurology.org//cgi/collection/nystagmus

Information about reproducing this article in parts (figures,tables) or in its entirety can be found online at:

http://www.neurology.org/misc/about.xhtml\#permissions

Information about ordering reprints can be found online:

http://www.neurology.org/misc/addir.xhtml\#reprintsus 